\title{
Training in higher education in the Covid-19 context: A case study of operation management training in a Business Innovation and Project Management Master
}

\section{Gorka Unzueta, Jose Alberto Eguren}

Industrial Organisation. Mechanical and Industrial Production department. Mondragon Unibertsitatea - Faculty of Engineering, Spain.

\begin{abstract}
The main objective of this paper is to describe the programme implemented through the use of information and communication technologies (ICT) for the development and acquisition of quality engineering (QE)-related competences in the context of the Covid-19 pandemic. In the 100\% face-to-face context, different products, such as catapults and paper helicopters, are used to apply the theoretical concepts of Six Sigma in a real environment, which would be impossible in an online or blended learning context. To overcome the difficulties due to the Covid-19 pandemic, a new programme has been defined that includes continuous ICT use, with a simulator of an injection process to generate the necessary data to develop practice. The programme and the simulator used have successfully replaced the practices and products previously used in a 100\% face-to-face environment, allowing students to acquire QE-related competences in a practical way in a non-face-to-face environment.
\end{abstract}

Keywords: Covid-19; teaching/learning strategies; higher education; simulator; online/blended learning; information and communication technologies (ICT). 


\section{Introduction}

In industrial organisations, a continuous improvement process (CIP) is a basic resource for generating long-term competitive advantage. To remain competitive over time, industrial organisations must develop a continuous improvement (CI) culture by implementing a CIP (Unzueta, Esnaola, \& Eguren, 2020). Universities have therefore incorporated training programmes into their curricula to develop competences related to $\mathrm{CI}$ and quality engineering (QE).

The traditional approach to teaching these competences comprises classroom lectures, where students do not have the opportunity to develop first-hand experience in the application of manufacturing techniques New training techniques that combine the teaching of elementary concepts with their application help create a suitable environment for learning and the development of the aforementioned competences, where practical knowledge is transferred and decision-making is worked on (Juan, Loch, Daradoumis, \& Ventura, 2017). In higher education (HE), different products, such as paper helicopters and catapults have been used to apply improvement techniques and methodologies in a face-to-face environment to help students acquire the necessary competences related to QE and DMAIC Six Sigma (SS) (J Antony \& Banuelas, 2002; Jiju Antony \& Jiju Antony, 2001; Eguren, Bertlin, Rehunen, \& Unzueta, 2020; Unzueta, Orue, Esnaola, \& Eguren, 2018).

However, the coronavirus pandemic (Covid-19) forced a transformation of the prevailing education models in HE. This transformation has focused on reducing classroom attendance through the support of information and communication technologies (ICT), necessitating new training models that combine the teaching of basic concepts with the practical application of these concepts through the use of ICT (Ali, 2020; Sá \& Serpa, 2020).

The aim of this paper is to describe how the transformation of the training and coaching process has been organised to train the students of the Master in Business Innovation and Project Management at Mondragon Unibertsitatea (MU) to acquire the necessary knowledge and skills in QE to help them develop skills in the closest possible environment to production. This transformation changed the process from a $100 \%$ face-to-face environment with faceto-face practice (Eguren et al., 2020) to a blended environment combining theoretical lessons with simulations based on ICT to overcome the limitations generated by the Covid-19 pandemic.

\section{Methodology}

To analyse the implementation of a new training programme, a qualitative case study research methodology was applied (Baxter \& Jack, 2008), and the following sources were used for data collection: direct observation, participant observation, interviews with students, student 
satisfaction surveys and the documentation and files generated by each student's team to solve the presented problem (Yin, 2013).

The training programme was based on dynamic learning (DL) (Baird \& Griffin, 2006), which is based on learning by doing and reflecting on the process. The team of professors developed and presented a problem, and the student teams developed a case in which they applied the improvement methodology based on the Six Sigma DMAIC (Pyzdek, 2003), which we call DMAIC-7P (Eguren et al., 2020) (Figure 1), to solve this problem.

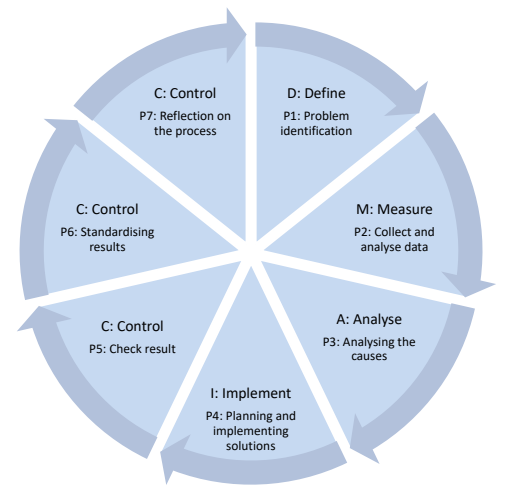

Figure 1. Six Sigma DMAIC - 7P Methodology.

The competence developed through the training programme is as follows: Uses quality tools to ensure that the production of a product or the provision of a service meets customer specifications.

Working in teams of four, the students applied the theoretical concepts they had been shown to a specifically designed problem or case, using as input the data provided about the problem to be solved. The developed case involves the optimisation of a plastic injection machine.

The process was carried out in a blended learning format, with the support of a Moodle platform where all the information was stored in a repository, including the theoretical files, the case description, the DMAIC-7P method templates, the injection process simulator in Excel format, the individual data of the plastic injection machine for each of the eight teams and remote access to Minitab software.

The training module lasted 20 hours and was delivered in two groups (morning and afternoon) to limit the number of participants and for teachers to have more time to attend to each team. Figure 2 shows the structure of the module and the contents to be covered in each session, including the type of session (face-to-face or online). In the face-to-face classes, priority was given to teaching the theoretical concepts and drawing conclusions from each phase of the methodology. In the online classes, tutorials were held with each team to guide their work. 


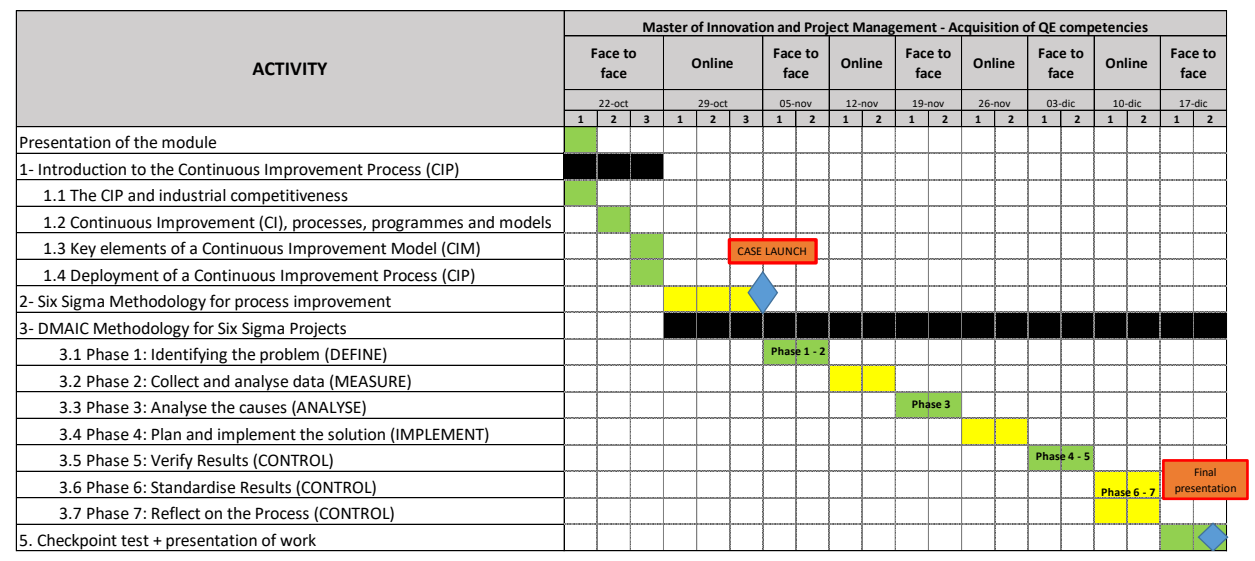

Figure 2. Module Structure and Planning.

The researchers observed the work done by each team and drew conclusions about the evolution of the training process. To evaluate the acquired skills, each team gave an oral presentation where they showed their results and reflected on the training process followed. Afterwards, the teachers and the researchers gave feedback on the observations made and the evaluation of the completed work.

The final evaluation of each student was carried out taking into account the group work performed, and an individual exam was administered through the Moodle platform, where the students demonstrated acquisition of the knowledge and competences related to QE.

\section{Developed Learning Process}

In the first training session, which was held face-to-face, the teaching team presented the concepts related to CI: CIP and industrial competitiveness, the differences between CI programmes, CI models and CI processes, the key elements of a CIP and how to properly deploy a CIP. During this session, the framework that the DMAIC-7P Six Sigma process improvement methodology focuses on was explained.

In the second session, held online, the DMAIC-7P methodology was explained in depth. In this session, the structure of the methodology, its phases and the main tools used in each phase were explained, as was the information deposited in the Moodle repository to be used by each team - the template for the application of the DMAIC-7P methodology, the injection process Excel simulator and the data to be used by each team. At the end of the session, the case to be developed was explained and given to each team. Each team was given different data, which forced the teams to develop their own cases.

In the subsequent sessions, each team developed the case individually using the data it received and the injection process simulator. The face-to-face sessions imparted the 
theoretical concepts and the application of the main improvement tools to the whole group and discussed the tasks carried out by each team so far. In the online sessions, each team developed its case telematically and held scheduled telematic meetings with the team of teachers.

To develop the first phase (P1: Define and identify the problem), the work teams used the information provided in the case description prepared for each team. Each team defined its own project, identifying a flow chart of inputs and outputs of the process using the SIPOC tool and the output of the desired injection process.

In the second phase (P2: Measure and collect data), the teams analysed the quantitative information prepared for each team using different tools (e.g. Ishikawa, histograms, Pareto, regression or time plots) to clearly identify their specific problem. As shown in Figure 3, each team used the simulator to define the approximate levels of the process parameters (input) and to achieve the desired injection process output.

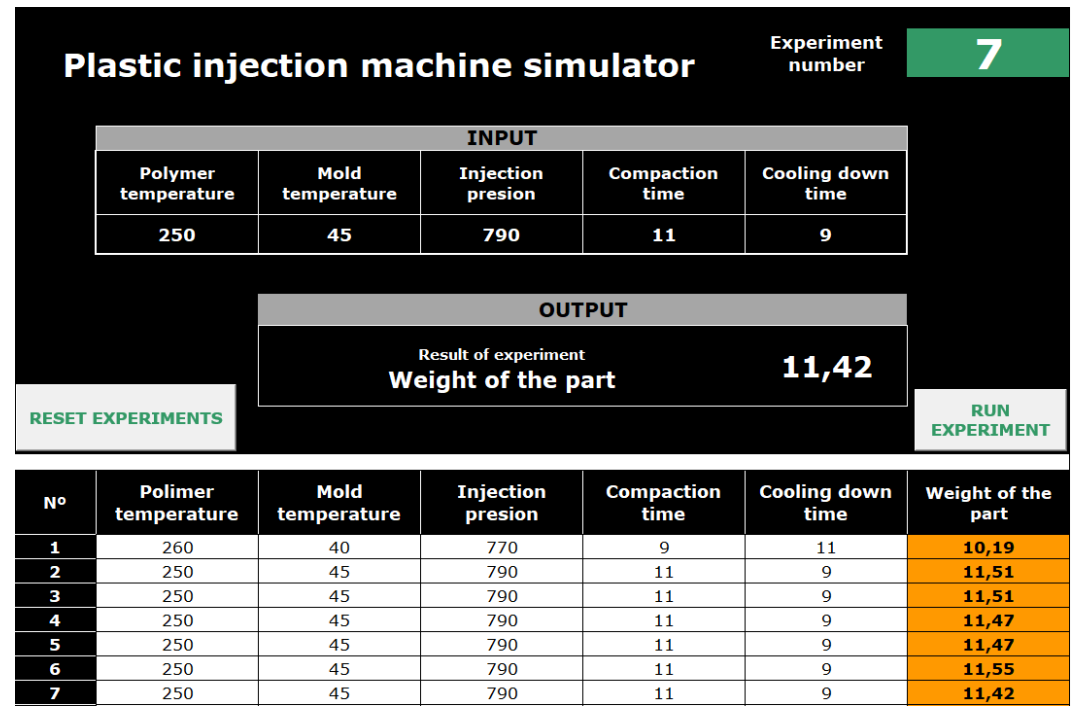

Figure 3. Injection Machine Excel simulator (Own elaboration).

In phases 3 and 4 (P3: Analyse; P4: Implement), which relied mainly on design of experiment (DoE) tools (e.g. ANOVA, factorial design- $2^{k}$, fractional factorial design-2 ${ }^{\mathrm{k}-\mathrm{p}}$, t-test and regression), each team precisely identified the appropriate levels of the input parameters of the injection process (Figure 4). In control phases 5 and 6 (P5: Verify and P6: Standardise), using the simulator to obtain the necessary data from the injection process, the work teams carried out the necessary data treatment to develop the control charts identifying the process control limits, establish the process control sheets and measure the process capacity (Figure $5)$. 

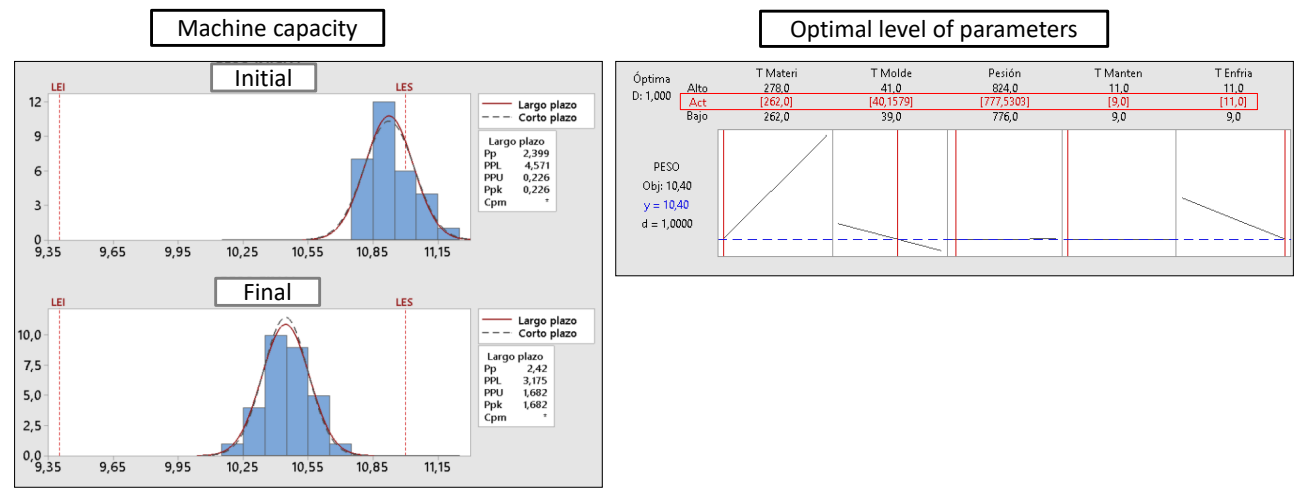

Figure 4. Results of the Analysis and Improvement of the Injection Process
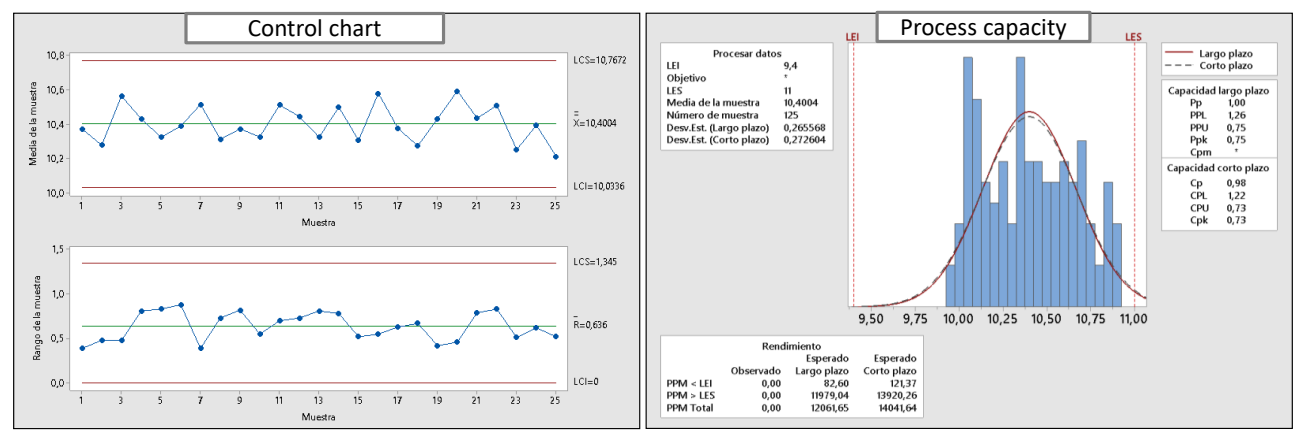

Figure 5. Example of a Control Chart and Process Capacity Analysis Completed by Students.

In the last phase (P7: Reflection), each team carried out a global reflection on the work developed and the methodology followed for its correct execution. Through group reflection, the students obtained a global vision of the improvement process, assimilating the improvement possibilities that the application of the DMAIC-7P methodology allows for achieving and understanding the relationship of the improvement tools applied individually. Table 1 shows the main improvement tools applied in each phase of the DMAIC-7P methodology. 
Table 1. Quality Tools Applied in each DMAIC Phase.

\begin{tabular}{|c|c|c|c|c|c|c|c|}
\hline & Define & Measure & Analyse & Implement & & Control & \\
\hline & Phase 1 & Phase 2 & Phase 3 & Phase 4 & Phase 5 & Phase 6 & Phase 7 \\
\hline & $\begin{array}{l}\text { Identify } \\
\text { the } \\
\text { problem }\end{array}$ & $\begin{array}{l}\text { Collect } \\
\text { the data }\end{array}$ & $\begin{array}{c}\text { Analyse } \\
\text { the } \\
\text { causes }\end{array}$ & $\begin{array}{l}\text { Plan and } \\
\text { implement } \\
\text { solutions }\end{array}$ & $\begin{array}{l}\text { Check } \\
\text { results }\end{array}$ & $\begin{array}{l}\text { Standardised } \\
\text { results }\end{array}$ & Reflection \\
\hline SIPOC & & & & & & & \\
\hline $\begin{array}{l}\text { Project } \\
\text { charter }\end{array}$ & & & & & & & \\
\hline Ishikawa & & & & & & & \\
\hline Histogram & & & & & & & \\
\hline Pareto & & & & & & & \\
\hline $\mathrm{R} \& \mathrm{R}$ & & & & & & & \\
\hline SPC & & & & & & & \\
\hline Regression & & & & & & & \\
\hline t-test & & & & & & & \\
\hline Time plot & & & & & & & \\
\hline ANOVA & & & & & & & \\
\hline $\operatorname{DoE} 2^{k}-2^{k-p}$ & & & & & & & \\
\hline
\end{tabular}

\section{Conclusion}

During the learning process implemented through the use of ICT in a blended learning environment, the students acquired technical competences (using quality tools to ensure that the production of a product or the provision of a service meets customer specifications), transversal competences (the ability to develop technical reports, develop oral presentations and conduct face-to-face and online teamwork) and competences related to the use of ICT.

In the reflection phase of the DMAIC-7P methodology, the students gained an overview of the process improvement methodology, identifying what new knowledge, skills and tools they applied during the teamwork. The results of the exam taken by each student showed whether the students acquired the pre-identified technical competence and necessary QE knowledge. In addition, the research team observed how the injection moulding process simulator satisfactorily replaced the products used in previous years for the practical 
application of the theoretical knowledge acquired in the $100 \%$ face-to-face classes, allowing the application of the DL model in a non-face-to-face format. The feedback received from the students was satisfactory and similar to that from previous years.

In conclusion, although non-face-to-face classes limited the capacity for interaction between teacher and students, based on the exam results and direct observation, the research team can confirm that the knowledge acquired enabled the students to develop competencies related to the use and application of quality tools, thus overcoming Covid-19 pandemic-related constraints.

\section{References}

Ali, W. (2020). Online and Remote Learning in Higher Education Institutes: A Necessity in light of COVID-19 Pandemic. Higher Education Studies, 10(3), 16. Retrieved from https://doi.org/10.5539/hes.v10n3p16

Antony, J, \& Banuelas, R. (2002). Key Ingredients for the Effective Implementation Six Sigma Program. Measuring Business Excellence, 6(2), 20-27.

Antony, Jiju, \& Jiju Antony, F. (2001). Teaching the Taguchi method to industrial engineers. Work Study, 50(4), 141-149. https://doi.org/10.1108/00438020110391873

Baird, L., \& Griffin, D. (2006). Adaptability and Responsiveness:: The Case for Dynamic Learning. Organizational Dynamics, 35(4), 372-383. https://doi.org/10.1016/j.orgdyn.2006.08.002

Baxter, P., \& Jack, S. (2008). Qualitative Case Study Methodology: Study Design and Implementation for Novice Researchers. The Qualitative Report, 13(4), 544-559. https://doi.org/10.1039/c6dt02264b

Eguren, J. A., Bertlin, T. A., Rehunen, J. H., \& Unzueta, G. (2020). Training in Quality Engineering Concepts and Skills: Case Study, Simulations Paper Propeller Using Six Sigma-Based Methodology. In Lecture Notes in Management and Industrial Engineering book series (LNMIE) (pp. 243-250). https://doi.org/10.1007/978-3-030-44530-0_29

Juan, A. A., Loch, B., Daradoumis, T., \& Ventura, S. (2017). Games and simulation in higher education. International Journal of Educational Technology in Higher Education, 14(1), 0-2. https://doi.org/10.1186/s41239-017-0075-9

Pyzdek, T. (2003). The Six Sigma handbook. New York, NY: McGraw-Hill Inc.

Sá, M. J., \& Serpa, S. (2020). The covid-19 pandemic as an opportunity to foster the sustainable development of teaching in higher education. Sustainability (Switzerland), 12(20), 1-16. https://doi.org/10.3390/su12208525

Unzueta, G., Esnaola, A., \& Eguren, J. A. (2020). Continuous improvement framework to develop cultural change. Case study, capital goods company. TQM Journal, 32(6), 1327 1348. https://doi.org/https://doi.org/10.1108/TQM-02-2019-0051

Unzueta, G., Orue, A., Esnaola, A., \& Eguren, J. A. (2018). Metodología del diseño de experimentos. Estudio de caso, lanzador. DYNA, 94(1), 16-21. https://doi.org/http://dx.doi.org/10.6036/8687 
Yin, R. K. (2013). Case study research: Design and methods (3th ed.). London: SAGE Publications Ltd. 